\title{
Lawrence Kohlberg, una obra en permanente construcción'
}

\section{Lawrence Kohlberg, a Work in Permanent Construction}

\author{
Jaime Yánez-Canal2 \\ María Angélica Fonseca Lamprea ${ }^{3}$ \\ Adriana Milena Perdomo Salazar ${ }^{4}$
}

Resumen

Este artículo, resultado de investigación documental del grupo Estudios sobre el Desarrollo Sociomoral, presenta un análisis sobre la historia y la evolución intelectual de Lawrece Kohlberg, pionero de la Psicología del Desarrollo Moral. Específicamente, el análisis de su obra gira alrededor de tres tópicos: la filosofía moral, la psicología del desarrollo y la pedagogía.

\section{Palabras clave}

Lawrence Kohlberg, desarrollo moral, filosofía moral, educación moral.

\section{Abstract}

This paper, documental research outcome of the "Estudios sobre el Desarrollo Sociomoral" research group, presents an analysis of the history and intellectual evolution of Lawrence Kohlberg, pioneer of Moral Development Psychology. Specifically, the analysis of his work revolves around three issues: moral Philosophy, developmental Psychology and Pedagogy.

Key words

Lawrence Kohlberg, moral development, moral philosophy, moral education.

Artículo recibido el 12 Agosto de 2011 y aprobado el 30 Marzo de 2012

1 Este documento es parte del proyecto de investigación "La evolución intelectual de Lawrence Kohlberg" financiado por la División de investigación sede Bogotá (DIB) de la Universidad Nacional de Colombia. Proyecto numero 14832.

2 Doctor en Filosofía de la Katholische Universität Eichstätt. Alemania. Profesor de la Universidad Nacional de Colombia jyanezc@unal.edu.co

3 Psicóloga de la Universidad Nacional de Colombia. Investigadora de la Universidad Nacional de Colombia mariett70@hotmail. com

4 Magister en Psicologíade la Universidad Nacional de Colombia. Profesora de la Pontifica Universidad Javeriana amperdomos@unal.edu.co 


\section{Introducción}

Lawrence Kohlberg es tal vez uno de los autores de obligada consulta en las discusiones sobre lo moral, la justicia y el desarrollo de juicios relacionados con la defensa y el respeto de los derechos y la dignidad humana. Este autor es usado como insumo conceptual por las más variadas concepciones de la moral $y$ es referencia necesaria para diferentes tipos de análisis dentro de los discursos preocupados por fundamentar las decisiones políticas y las formas de argumentación de tipo ético.

Sin temor a exagerar, Kohlberg es de esos pocos autores que no solo ha logrado que se asocie a su nombre un particular campo investigativo, sino que ha desbordado los a veces estrechos límites entre las disciplinas. Su nombre se ha convertido en patrimonio de muchas disciplinas que encuentran en sus ideas un trasfondo para analizar el fenómeno humano por variados niveles y que les permite establecer unos criterios de legitimidad en la obligatoria tarea de construir reglas y acuerdos para la convivencia y la confianza social.

Sin embargo, a pesar de la importancia y el impacto que ha tenido la obra de Kohlberg en variados discursos y disciplinas, en muchas ocasiones ha sido pobremente conocida y superficialmente estudiada.

Muchas veces algunos autores se convierten en íconos por haber presentado un campo de estudio y una propuesta novedosa, por la fortaleza de su argumentación, por la capacidad integradora de su discurso, o por el desconocimiento y superficialidad en que es analizada su obra por autores de lejanas actividades intelectuales. Posiblemente muchas de estas razones puedan presentarse para exaltar el valor intelectual de la obra de Kohlberg, incluyendo la costumbre intelectual de considerar las disciplinas alejadas a la propia como universos unificados y como terrenos donde se habrían de importar ideas sin necesidad de que pasen por el severo y riguroso análisis que puede ejercerse en la propia disciplina.

Esta última afirmación no pretende desconocer ni la importancia de Kohlberg, ni la relevancia que tuvo su obra para las discusiones contemporáneas de lo moral, solamente quiere despertar el interés por iniciar en nuestro medio un trabajo más profundo sobre su obra, un análisis que intente mostrar la historia y evolución de su trabajo intelectual, y que intente contextualizar las razones que lo llevaron a plantear algún concepto o reflexión particular.

Como parte de esta introducción creemos conveniente hacer algunas aclaraciones sobre la obra de Kohlberg que motivaron el desarrollo de este escrito. Como primer punto creemos que la teoría de este autor no constituye un sistema organizado y armónico donde sus conceptos y explicaciones se hayan mantenido a través de sus treinta años de investigación. Realmente, como señalan Eckensberger \& Reinshagen (1980) Oser (2001) Lind (1999), se puede encontrar lo contrario, una constante variación y reinterpretación de sus datos empíricos e incluso formulaciones contradictorias a nivel conceptual.

Algunos ejemplos que podemos citar para ilustrar algunas de las anteriores afirmaciones los podemos encontrar en su texto Essays in moral development, Volume II, The psychology of moral development (1984/1992)5. En este texto, cuando Kohlberg explica en la página 623 las operaciones de justicia propone cinco características; posteriormente en la página 633 propone solamente tres de estas características. De la misma manera en este texto podemos encontrar descripciones diferentes del estadio 2 del desarrollo.

Si se encuentran estas contradicciones o imprecisiones en un mismo texto, es de suponer que esto se hace más notorio si se comparan diferentes obras del mismo autor. La ubicación de las respuestas de los sujetos en un particular estadio varían de acuerdo a como fue variando su concepción de los estadios o fases del desarrollo, o como fue transformando sus estrategias metodológicas (Kohlberg en sus estudios longitudinales volvía constantemente sobre los casos analizados en sus primeras investigaciones) (Peltzer, 1986). De la misma manera, estas variaciones conceptuales se pueden observar si se analizan su concepción de lo moral, la nominación de sus esta-

5 Debido a nuestro interés de rastrear las variaciones conceptuales de Lawrence Kohlberg pondremos siempre la fecha de la edición original en inglés y la versión en español consultada. Así por ejemplo en 1984/1992 la primera fecha corresponde a la edición original en inglés y la segunda a la edición en español consultada. 
dios, el estadio que habría de considerarse final en su escala de desarrollo, la conceptualización sobre la relación de la forma y el contenido, la estrategia pedagógica para facilitar el desarrollo moral, las edades en donde se consolidaría un determinado estadio moral, los casos anómalos dentro de su investigación empírica, los debates o comprensiones de otros autores o teorías, la utilización de teorías opuestas e irreconciliables para sustentar algunas de sus ideas y muchas otros aspectos esenciales de su teoría.

Estas variaciones conceptuales muchas veces dificultan el estudio de su obra, ya que no simplemente se presentan en momentos que pudieran interpretarse como un proceso de construcción y desarrollo de su teoría, sino que pueden ser completamente circulares, o pueden darse con relecturas de sus anteriores trabajos, o pueden deberse a que su documentación no mantiene criterios estrictos en el manejo de las fechas de sus publicaciones ${ }^{6}$.

Para ilustrar los cambios circulares y las relecturas de sus trabajos podemos referirnos a algunos conceptos dentro de su larga trayectoria intelectual. Por ejemplo, en su tesis doctoral caracterizó sus estadios según el esquema weberiano de "tipos ideales", caracterización que abandonó desde los años 60 para retomarla en sus últimos trabajos. De la misma manera el estadio 6 del desarrollo lo puso y lo quitó como estadio final del desarrollo normal del ser humano en varias oportunidades. Igualmente afirmaba que en su primera obra (su tesis doctoral) había tenido en cuenta, para la caracterización de lo moral, la obra de Robert Hare, aunque solo de manera explícita y de manera extensa es referenciado posteriormente; o que la conceptualización de Habermas (1979) podría observarse en muchas de sus ideas iniciales, cuando tuvo en cuenta las formulaciones de este autor solamente en sus obras finales. De la misma manera podemos ver

6 Peltzer (1986) afirma que Kohlberg cita sus textos con fechas diferentes a como fueron editados, o reedita textos anteriores sin aclaración alguna, o se refiere a trabajos que estarían en preparación 0 en prensa y que nunca fueron editados, o hace transformaciones de algunas de sus publicaciones iniciales a los que consideraba en su primera versión como "obra gris". en sus discusiones el variado significado que le da a otras teorías psicológicas, filosóficas o sociales. Erikson, Loevinger (1977), Kegan (1982), Gilligan (1977, 1982/1985), y muchos otros autores fueron utilizados por nuestro autor para muy variadas argumentaciones y con muy diferentes valoraciones.

Siendo conscientes de muchas de estas dificultades de la obra de Kohlberg, tenemos que establecer los límites de nuestra indagación. No es nuestro propósito hacer un análisis exhaustivo de la obra de este autor, ni rastrear los hilos perdidos que restituyan la coherencia de su obra, ni hacer un análisis minucioso de cada uno de los problemas que abordó este autor, ni mucho menos contextualizar hasta el más mínimo detalle muchas de sus ideas y de sus confrontaciones con muchos de sus contradictores.

Nuestro trabajo simplemente espera mostrar algunas de sus ideas y señalar algunas de sus variaciones conceptuales, especialmente aquellas referidas a la caracterización de sus estadios, a sus concepciones pedagógicas y algunas discusiones filosóficas que Kohlberg dio en algunos pocos textos. De la misma manera habremos de presentar algunas de las discusiones en las que participó el creador de la psicología del desarrollo moral y algunas preguntas y problemas de investigación que ha suscitado su enorme obra.

Posiblemente las contradicciones o incoherencias del pionero de la psicología del desarrollo moral se deban a sus variadas preocupaciones investigativas, a las dificultades que usualmente se presentan en todo colonizador de un nuevo campo investigativo, a las dificultades de todo discurso que intenta unir preocupaciones de diferentes disciplinas o diferentes niveles de análisis, o a cualquier otra razón que apenas esperamos esbozar en este corto artículo.

La obra de Kohlberg es un espacio donde se presentan algunas tensiones tanto de la filosofía moral como de la psicología y la pedagogía. La oposición entre lo universal y lo particular, entre lo formal y el sentido, entre lo cognitivo y lo comunitario se actualiza en un espíritu investigativo que en ánimo de ofrecer un discurso coherente se desgarra ante argumentos permanentemente revividos. 
Independientemente de la posición con la que el lector pueda simpatizar, e independientemente del mayor reconocimiento que alguna de ellas pueda haber logrado en ciertos ambientes académicos o en ciertos momentos históricos, es claro que la obra de Kohlberg puede presentarse como un espacio de confrontación de diferentes conceptualizaciones. Nuestro autor, que a veces puede aparecer de manera metafórica como el médium donde estos diferentes poderes conceptuales se debaten a muerte, oscila permanentemente entre una y otra posición por intentar atender a demandas tanto normativas como empíricas.

De la misma manera las posiciones opuestas de la psicología del desarrollo se expresan en diferentes momentos y con variada intensidad en los escritos de Kohlberg. En este terreno, nuestro autor se debate entre explicaciones cognitivas y culturales, o entre caracterizaciones formalistas y hermenéuticas de los juicios y acciones morales.

A continuación nos referiremos a las variaciones conceptuales del profesor de Harvard en los campos de la filosofía moral, la psicología del desarrollo y la pedagogía.

\section{La delimitación de lo normativo}

Podemos establecer los cambios de Kohlberg alrededor de lo normativo, o de su concepción de ética según los autores de la filosofía moral retomados por él. Veamos cómo nuestro autor presentó sus ideas sobre lo moral.

\section{Primeras formulaciones sobre lo moral}

En su tesis doctoral, escrita en 1958, Kohlberg retoma algunas discusiones de los teóricos del contrato social. Para estos autores, dentro de los que podemos incluir a Hobbes, Locke, Rousseau y Kant, la preocupación central era establecer los criterios que asegurarían la justicia en las sociedades y proporcionarían legitimidad a los estados.

Debido a que las normas y el respeto a las instituciones ya no se lograban por referencia a Dios o a las disposiciones de la tradición, los autores citados debieron establecer nuevos parámetros para el ejercicio de lo moral. Lo primero que debió establecerse en estas posturas iniciales de la modernidad fue la autonomía y la libertad del ser humano y con ella unos derechos naturales y una idea de razón que propiciaba la escogencia de variados planes de realización individual y el establecimiento de contratos sociales.

$\mathrm{Al}$ ser humano ${ }^{7}$ debería otorgársele no solo unas cualidades particulares, sino unos derechos que deberían ser universales y presociales. Para evitar que las variaciones históricas determinaran la idea de los derechos y el aseguramiento de la igualdad, se establecieron unos derechos ligados a todo ser humano como propios de su naturaleza. El derecho a la vida, la libertad y la propiedad8 serían, para los primeros teóricos liberales de la modernidad, derechos naturales que conducirían a los sujetos a establecer acuerdos, o contratos sociales. El contrato social era un convenio establecido racionalmente 9 para asegurar el respeto a estos derechos.

Gracias a la idea de derechos universales se garantizaba el trato igualitario de todos los seres humanos y se establecían normas públicas para su respeto. Una idea esencial de estas propuestas de la filosofía política era separar el espacio público del privado, siendo el primero el único donde podrían establecerse acuerdos de manera recíproca y justa.

La justicia acabó convirtiéndose en el concepto central de las discusiones morales, ya que era el concepto que refería a las relaciones sociales y a las

7 Obviamente, las concepciones sobre la naturaleza humana variaban en estos autores. No solamente diferían sobre cómo entender los impulsos o características presociales del ser humano, sino también en cómo se propiciaban los acuerdos humanos y sobre cuales derechos deberían establecerse como naturales.

8 Sobre el valor dado a cada uno de estos derechos y la primacía que se le pudiera otorgar a alguno de ellos, se presentaron muchas diferencias entre los primeros autores del contrato social y muchas formulaciones posteriores de toda esta tradición liberal.

9 El concepto de lo racional para los autores del contrato social, exceptuando a Kant (1785/1959), consistía en el cálculo de consecuencias, donde un sujeto procuraría siempre maximizar sus beneficios. Un sujeto establecería un contrato porque este le habría de garantizar mayores beneficios, así este le implicara algunos sacrificios o limitaciones a sus demandas personales. Esta idea de racionalidad, adquirió su mayor reconocimiento en las posturas utilitaristas y en las posteriores elaboraciones técnicas de los economistas que establecerían sus evaluaciones sobre la justicia según cálculos matemáticos derivados de la teoría de juegos y de la decisión. 
normas que garantizarían el respeto de los derechos naturales. La justicia empezó a asociarse a la imparcialidad, y al trato igualitario ante la ley. En los espacios privados el mismo sujeto racional tendría la completa libertad para disponer sobre sus bienes, sus afectos y sus particulares planes de realización ${ }^{10}$.

En su tesis doctoral, Kohlberg asume muchas de las ideas ${ }^{11}$ de los teóricos del contrato social para presentar su idea de lo moral (Des Jardin, 1980). Por un lado, establece unos derechos universales que todo hombre habría de tener, y por otro, establece una capacidad racional que posibilitarían los acuerdos y las decisiones libres de los sujetos tanto en los principios morales que asumirían para su vida, como en los planes de realización individuales. Los derechos que plantea Kohlberg como universales son el derecho a la vida y el respeto a la libertad. Garantizados esos derechos, los sujetos en su máximo nivel de desarrollo podrían escoger sus principios morales y determinar sus planes de vida.

Esta concepción moral está estrechamente ligada a la justicia, ya que esta se asocia a la idea de imparcialidad y al trato igualitario en pos del desarrollo personal y el reconocimiento de las particularidades y necesidades de cada sujeto. El sujeto más desarrollado en la escala de Kohlberg, que posee un juicio semejante al formulado por los filósofos políticos, corresponde a aquel que es capaz de pensar en principios universales que garanticen el respeto a los derechos y que pueda establecer procesos de negociación con los otros, según pautas de reciprocidad.

Esta primera postura de Kohlberg sobre lo moral puede presentar una serie de dificultades. Unas dificultades se refieren a como especificar el valor de los derechos y si estos tienen un valor universal

10 Para los filósofos griegos e incluso para ciertos filósofos morales escolásticos como Santo Tomás, la justicia era una virtud asociada a los individuos y a particulares concepciones de realización. La separación entre lo público y privado es una diferenciación de la modernidad, donde la justicia es solo parte de lo público y de lo que puede ser negociado bajo la normatividad moral.

11 En este trabajo se presentan varias concepciones de lo moral. Unas referidas al problema de la acción y la motivación moral y otro relacionado con el criterio fundamental y universal de lo moral. Sobre estos últimos aspectos se centra nuestro análisis, ya que van a ocupar un lugar central en toda la preocupación cognitiva de Kohlberg. sin ninguna evaluación contextual, o sin ninguna jerarquía entre ellos que evite su confrontación. La otra dificultad es si un principio moral es aquel que un individuo de manera independiente pueda establecer sin un parámetro externo que evite la trivialización ${ }^{12}$.

Veamos estas dificultades de manera rápida. Si el derecho a la vida se plantea de manera universal ¿qué posición habría de tomar un individuo si por el respeto de ese derecho sea por otro esclavizado? El oponerse a la limitación de la libertad puede traer como consecuencia el riesgo de la vida del otro, o de uno mismo. Para evitar ese riesgo y no atentar contra la vida ¿debemos someternos a la privación abusiva de la libertad? O ¿qué pasaría si, por no afectar a otra persona, esta amenaza mi vida? Igualmente hay infinidad de variaciones culturales en donde la vida no es un principio con similar significación ${ }^{13}$. Como se puede deducir de estos casos es conveniente establecer unos criterios claros para solucionar este tipo de conflictos entre derechos.

Igualmente, el establecimiento de principios de manera independiente y el planteamiento tan general del proceso de negociación, como lo hace Kohlberg ${ }^{14}$, puede conducir a formulaciones de

12 Como decíamos en una nota anterior los teóricos del contrato social difieren sobre el valor o primacía dada a cada derecho y sobre cómo entender lo racional. Si bien Kant establece lo racional como un operar de un individuo independientemente de las consecuencias en ánimo de garantizar la dignidad humana representada esencialmente en su libertad, para Locke la propiedad es un elemento fundamental y la libertad es asumida simplemente como la capacidad de decidir personalmente planes o acciones propios del espacio privado. Kohlberg, en su tesis doctoral, no explícita estas diferencias ni establece jerarquías entre derechos, ni parámetros claros para decidir cuando estos entren en conflicto o cuando se confronten con otros problemas no necesariamente morales.

13 En algunas culturas africanas, los parientes más cercanos pueden asesinar a sus padres en su periodo de adultez, ya que simplemente quieren asegurarles unas buenas condiciones en su otra vida. Si se "les manda con saludables condiciones físicas al otro mundo" se está velando por su seguridad. La muerte en esta vida asegura una más larga vida en la "otra vida".

14 Y Piaget con él. Piaget, siguiendo parámetros similares, establece como niveles altos de desarrollo moral el que un sujeto pueda establecer reglas por consenso y por un proceso de negociación con sus pares. Pero esta condición no es necesariamente un problema moral. En otras palabras, el que los niños convengan cambiar las reglas del juego de canicas no hace a estas reglas, ni al juego de canicas, un problema moral. De la misma manera, el que una sociedad establezca por votación, o por cualquier otra estrategia 
máximas no necesariamente morales. El que un sujeto formule una norma como universal y que él alegue haberlo hecho de manera autónoma no justifica su decisión, ni convierte la norma en algo de aceptación universal.

No es propósito de este corto artículo analizar si la idea de racionalidad o de libertad de algunos teóricos del contrato social conducen necesariamente a las dificultades anteriormente señaladas, o si estos problemas se deban a la traducción psicológica de formulaciones propias de espacios públicos y de la filosofía política. Basta señalar que estos problemas no son abordados de manera explícita por Kohlberg, a pesar de que sus posteriores reflexiones parecieran dirigirse a enfrentar algunos de ellos. Veamos algunos de sus desarrollos posteriores.

\section{Hare y la idea prescriptivista de lo moral en la obra de Kohlberg}

Retomemos la idea planteada anteriormente: la formulación general de una regla no la convierte en un problema moral. Si pensamos en una convención social de universal aceptación, podemos pensar en la necesidad de agregar algunas otras características para hablar de una norma como moral. Por ejemplo, podemos pensar como universal, sin que eso las haga reglas morales, que todos los carros conduzcan por el carril derecho de las calles (podría formularse esa conducta como universal en contra de las disposiciones de algunos países de habla inglesa), o podemos reconocer como una pauta universal que las personas se dirijan a sus compañeros con ciertas normas de cortesía, o que todos tengamos unas normas mínimas de aseo en los espacios de consumo alimenticio, o en los espacios religiosos, o que la gente se vista de acuerdo a la importancia de cada ocasión. Posiblemente estas normas sean parte de los buenos modales, en los que debe ser educado un

que conduzca a un consenso, la eugenesia o la esclavitud, no significa que ese acuerdo sea avalado por un tribunal moral. El proceso de negociación puede ser una condición necesaria, pero los parámetros morales por donde deben transcurrir los acuerdos deben establecerse desde otro espacio. Esa es una preocupación kantiana que es tratada de manera muy rápida por Kohlberg en su tesis doctoral, a pesar de que afirma seguir muchas de sus formulaciones. niño, pero nadie descalificaría en términos morales el que alguna de ellas no se siguiera de la manera esperada. Estos ejemplos ilustran por qué no toda norma es una norma moral, y por qué no se deben relacionar, de manera necesaria, las costumbres de los pueblos con valores morales.

A pesar de que tanto las normas morales como las sociales pueden tener un carácter obligatorio y propender por su aceptación universal15, deben establecerse unas diferencias entre ellas. Las normas morales deben ser universales y tener además un carácter prescriptivo; deben seguirse en todas las situaciones y tienen un carácter de obligación para todos los sujetos.

Con esta caracterización formulada por R. M. Hare (1963) 16 ya podemos empezar a establecer unas diferencias entre las normas sociales y las morales. Una norma social puede ser universal pero no tiene necesariamente un carácter obligatorio. $O$ puede tener un carácter obligatorio, pero no necesariamente opera de manera universal. Las normas morales deben tener, según Hare, estas dos características.

Pero hasta ahora hemos dado un solo paso en la caracterización de lo moral según las indicaciones de Hare. Los siguientes problemas tienen que ver con la idea de lo universal y con el carácter de obligación y si estas características, ya formuladas como necesarias, son suficientes para determinar una conducta o un juicio como moral. Presentemos inicialmente el problema referido al carácter de obligación. Hagámoslo con una serie de ejemplos.

15 Es claro que la idea de lo universal en la ética tiene un carácter diferente al que se asume en las ciencias. Lo ético se propone como una tarea que busca asegurar el trato digno a todos los seres humanos y con él se propone garantizar la igualdad de los mismos. La búsqueda de aquello que debe asegurarse como más digno del ser humano es una tarea a la que toda sociedad está condenada. Independientemente de la imposibilidad de establecer acuerdos definitivos, todas las sociedades buscan establecer normas que aseguren una adecuada convivencia social y que garanticen el respeto de unas demandas mínimas de humanidad. La búsqueda de esas normas de general aceptación es el problema que motiva todos los discursos éticos. Independientemente de que las formulaciones existentes en la historia de la ética hayan sido aceptadas como universales, todas se proponen con el propósito de incluir a todos los seres que se reconocen como semejantes.

16 En este punto, Hare sigue las diferenciaciones que hace Kant entre el imperativo hipotético y el categórico. 
Imaginemos una persona con un retardo intelectual severo que tiene como tarea, en un pequeño pueblo perdido en los Andes colombianos, hacer las diligencias y los encargos de todos sus habitantes. Este sujeto hace el mercado, paga los recibos y las deudas de sus habitantes y siempre lo hace sin tomar para sí ni un solo centavo del cambio o del dinero a él confiado. Antes de calificar a este personaje con los más altos puntajes en cualquier escala de honradez o de desarrollo moral, es conveniente que ampliemos los detalles de la historia. Este sujeto, que no tiene las más mínima idea del valor del dinero, simplemente se encarga de llevar en una bolsa los recibos con el dinero a personas específicas dentro de su pueblo, que son los que hacen las cuentas y depositan de manera correcta el dinero sobrante en la misma bolsa que nuestro personaje transporta de regreso hacia su respectivo destinatario. Cada persona, tendero o cajero correspondiente le indica a nuestro personaje hacia dónde debe dirigirse y a quién debe entregarle el contenido de su bolsa. Para hacer más efectivo el procedimiento, este mandadero hace una sola tarea por recorrido, así que la persona que hace el encargo, como aquella que recibe la petición, enviada a través del mensajero, sabe que el otro sabe que fue enviado y que debe ser devuelto. Incluso el mensajero es eximido de cualquier información verbal, ya que en su bolsa pueden ir instrucciones escritas que cada destinatario debe atender. El comportamiento del mensajero no puede calificarse como adecuado moralmente, ya que él no tiene la más mínima noción del dinero, ni del sentido de sus acciones.

Así mismo, no todos los personajes del pueblo que depositan de manera correcta el cambio en la bolsa del mensajero pueden recibir honrosos calificativos morales. Si algunos simplemente lo hacen porque saben que el encargado de la diligencia solo hace una tarea por vez y su ocasional patrón sabe exactamente cual fue el resultado de su encargo, no se pueden calificar de seguidores de una norma moral. Incluso si la "bolsa" del mensajero puede accidentalmente ocuparse con dos encargos, un tendero puede no recibir el titulo de honesto si solo obra correctamente por el riesgo de ser descubierto y por el temor que eso le genera de perder su clientela.
Con estos ejemplos extremos, podemos concluir que una conducta, que podría ser calificada por terceros como adecuada moralmente, demanda de parte del sujeto que la realiza una conciencia, o al menos un juicio de por qué la ha realizado. En otras palabras, no basta que alguien cumpla una norma, ni que la sienta como una obligación perentoria para que sea calificado como correcto moralmente. Es preciso que el sujeto esgrima unas razones, o tenga una explícita intención del por qué esta tiene un carácter prescriptivo.

Las normas morales, o mejor, los principios morales ${ }^{17}$, son criterios generales que deben ser justificados por el sujeto que los sigue. Seguir una norma, prima facie, no es garantía de un adecuado comportamiento moral. El sujeto debe tener la intención de hacerlo y debe mostrar un razonamiento explícito de por qué sigue unos determinados principios.

Pero si es requisito indispensable, que el sujeto argumente el por qué respeta una norma, es necesario, igualmente, el establecer cómo operan esos niveles "críticos, según la expresión de Hare (1963). Si dos normas igualmente obligatorias entran en conflicto debe establecerse un nivel superior a ellas para solucionar el impasse. En otras palabras, un sujeto debe poseer algunos criterios explícitos, o unos principios, que le permitan solucionar variados dilemas morales. Veámoslo con algunos ejemplos.

Retomando un ejemplo ya presentado en este texto, el conflicto entre el respeto a la vida y la limitación de la libertad por un tirano, nos podemos preguntar qué razones podemos esgrimir para solucionar el dilema y justificar una determinada acción cuando, como en este caso, los dos valores presentados nos demandan una consideración universal y prescriptiva. De la misma manera podemos pensar en los casos de la eutanasia, cuando la idea de vida adquiere otra significación. El cumplimiento de promesas, la intimidad, la propiedad y otros valores igualmente pueden demandar un nivel más alto de

17 Hare no especifica el nivel de generalidad de la regla, ni el peso que deben tener los significados particulares para decidir cuándo dos principios están en conflicto. Ese es un problema al que nos referiremos a continuación. 
abstracción cuando entre ellos se presenta algún tipo de conflicto.

Hare (1963) propone ese nivel de principios como necesario para solucionar los dilemas morales; solo una persona puede presentarse como moral si, poseyendo una adecuada capacidad de argumentación y de sensibilidad a las necesidades de los otros, tiene una serie de principios que le permiten establecer un determinado peso a cada valor presente en las disputas, según sean las circunstancias y demandas de los participantes.

Pero si Hare propone este nivel "critico" como un ingrediente fundamental para determinar el nivel de juicio moral, es justo decir que en este autor no se especifican esos principios que tendrían ese carácter abarcador, ni que facilitarían la solución de los dilemas morales. Su preocupación metaética ${ }^{18}$ lo alejó de estos aspectos normativos, que son fundamentales para abordar dilemas específicos. Pero volvamos Kohlberg y cómo asumió las ideas de Hare.

Kohlberg, en los años 60, siguió estrictamente las sugerencias conceptuales de Hare y estableció una separación entre las acciones de los sujetos y sus juicios morales, que eran calificados según variados niveles de "universabilidad" y de prescriptividad. Igualmente estableció una separación entre las disciplinas empíricas y los niveles de justificación moral. Las disciplinas empíricas tienen como preocupación describir las conductas y acciones morales, pero no pueden fundamentar, ni justificar cómo y cuáles son las maneras de operar de los discursos morales (Kohlberg, 1969).

El último nivel de razonamiento moral era caracterizado en términos del carácter universal y prescriptivo y según fuera la capacidad explicita del sujeto de establecer unos principios que le permitirían solucionar sus dilemas morales ${ }^{19}$. Cuando

18 La preocupación de la metaética está dirigida a analizar las maneras en cómo se constituyen los discursos morales, y no en establecer parámetros o propuestas específicas que permitan abordar los problemas que tienen que ver con la moral. Ese tipo de análisis formal (recuerden que estas preocupaciones metaéticas se originaron en los análisis del lenguaje dentro del positivismo y la filosofía analítica,) solo establece similitudes entre los discursos morales, pero no evalúa el peso o valor de los principios normativos específicos.

19 En esta época, el concepto de reversibilidad piagetiana se asociaba hablaba de principios, era bastante impreciso en su caracterización y los definía como cualquier tipo de regla "auto-escogida", que respetara la autonomía y la reciprocidad, tal como las formuló en su tesis de doctorado.

Pero si Hare posibilitó a Kohlberg establecer unos criterios para caracterizar los juicios morales en su máximo nivel de desarrollo, y con ello establecer un fundamento de los discursos morales, la imprecisión sobre su idea de principios seguía manteniéndose. La caracterización de un principio como una norma general, como lo estableció Hare, o la referencia a principios auto-escogidos, como lo formuló Kohlberg en sus primeros trabajos, no garantizaban de manera precisa establecer las maneras en cómo se habría de solucionar un dilema moral. Posiblemente la metaética de orientación prescriptivista le permitió a Kohlberg precisar los aspectos formales del razonamiento moral, pero no dotó de cuerpo el análisis que demandan los dilemas morales. Estas dificultades lo condujeron nuevamente a las discusiones sobre la justicia dentro de las teorías del contrato social y especialmente a la obra de John Rawls.

\section{El neocontractualismo de Rawls y la idea moral de Kohlberg en los años 70}

La Teoría de la justicia de John Rawls (1971) tuvo un impacto enorme en las discusiones sobre el concepto de justicia en la filosofía política y en la obra de Lawrence kohlberg. Veamos algunas de sus ideas y su influencia en los planteamientos Kohlbergianos.

Unas de estas ideas es la relacionada con el concepto de libertad y el de mérito. Usualmente el concepto de libertad se ha establecido alrededor de la acción consciente y deliberada que un sujeto realiza en ánimo de satisfacer alguna de sus necesidades. Las propuestas iniciales del liberalismo abogaban por establecer la libertad de acuerdo a la capacidad de decidir y de actuar de un individuo.

\footnotetext{
a los conceptos de universabilidad de Hare. El sujeto en su máximo nivel de desarrollo era ya capaz de operar con juicios reversibles, que se entendían como la capacidad de considerar las demandas y los derechos de los otros. Más adelante abordaremos las concepciones psicológicas asumidas por Kohlberg.
} 
Si bien las primeras formulaciones de la libertad como derecho tuvieron un papel revolucionario en tanto se estableció como reacción y resistencia a la tradición y al poder de la Iglesia, es preciso agregar otros elementos para poder asegurar un trato digno a los seres humanos. Pensemos en un esclavo, para ilustrar el sentido de libertad que queremos resaltar. El esclavo puede reclamar que él ha decidido "libremente" permanecer en su esclavitud y que cualquier oposición a su deseo consentido no respeta su consciente y deliberada decisión. Pensemos igualmente en un preso, o en una persona, que ha sido confinada contra su voluntad, en una caverna, o en un cuarto oscuro, toda su vida. Si le preguntamos a esta persona cuáles son sus deseos, posiblemente nos demande (suponiendo que sea capaz de formular alguna demanda, claro) un colchón nuevo, o una mayor cantidad de velas, más no necesariamente habrá de considerar su liberación.

Con estos ejemplos, algo crueles, podemos postular que el concepto de libertad exige una consideración de la dignidad, por encima de lo que el sujeto ha aprendido a desear, o a considerar como lo adecuado. El concepto demanda una consideración de la igualdad en términos de un conocimiento pleno de las posibilidades humanas, o al menos la consideración de aquellas circunstancias que impiden que el sujeto pueda decidir de manera libre. $\mathrm{Si}$ bien nadie puede determinar las condiciones de la absoluta libertad, es tarea de la ética empeñarse en ese esfuerzo, por lo menos para ir ganando claridad en las maneras en cómo podemos entender y reclamar una cada vez más plena dignidad.

Si los ejemplos presentados nos ayudaron a entender que no siempre el ser humano cuenta con las posibilidades para su obrar libre e igualitario, podemos entender más fácilmente la formulación de Rawls. Al abusar de nuestras analogías, podemos entender que en las sociedades humanas existen ciertas poblaciones que, careciendo de las mínimas condiciones de existencia, han crecido con unas notorias limitaciones para escoger libremente sobre sus opciones de vida. La poblaciones más pobres, o más alejadas de los progresos de la civilización, o más discriminadas, han contando con menos beneficios y posibilidades para su desarrollo y por lo tanto los rangos de acción de su libertad son bastante restringidos.

Para Rawls (1971), el lugar que una persona ocupa en una sociedad es un acto de suerte que no tiene nada que ver con su responsabilidad. Si una persona nace en un estrato social bajo, donde no ha contando con mínimas condiciones de salubridad y educación es claro que no podrá contar con las mismas oportunidades en el mundo laboral, ni en otros espacios de una sociedad. El mérito, que era esencial para las primeras teorías del contrato social y para la idea de libertad que estos autores defendían, es puesto a un lado en la formulación de Rawls. La mayor inteligencia, así como la mejor educación, o las particulares concepciones de realización, son el resultado de los azares de la naturaleza y no cualidades de los individuos que deban asegurarse y respetarse en toda circunstancia.

En función de lo anterior, Rawls ${ }^{20}$ propone como parte de la idea de justicia que el Estado intervenga de manera activa tratando de nivelar las diferencias. El Estado debe asegurar que los recursos sociales sean mejor distribuidos, con el propósito de asegurar en un futuro el ejercicio pleno de la libertad y la igualdad de todos los ciudadanos. Esta es su teoría de la justicia como equidad.

Kohlberg, en los años 70 (1973, 1977, 1978), presentaba su teoría como una teoría de la justicia como equidad, siguiendo las formulaciones y las ideas centrales de Rawls. En estos años ya no aboga por el respeto y aceptación universal de unos derechos naturales, como los había entendido en los años anteriores, y establece unos criterios más precisos para evaluar los juicios de los sujetos en su nivel más alto de desarrollo. La justicia no consiste simplemente en establecer los acuerdos de manera consensuada, ni únicamente en un concepto general de reciprocidad, ni en la justificación de unas normas libremente escogidas, sino en una decisión que

20 Los detalles de la argumentación de Rawls son pasados por alto. Igualmente las diferentes concepciones de justicia, libertad e igualdad son omitidas en este texto. Nuestra preocupación es simplemente ilustrar algunas de las ideas que más influyeron en la obra de Kohlberg. 
establezca las demandas y los reclamos de aquellos que están en condiciones desfavorables en los intercambios sociales.

Pero si bien la teoría de Rawls le había permitido resolver algunos conflictos entre valores, también lo enfrentó a una serie de dificultades, muchas veces señaladas por sus críticos. Gilligan (1977), Fowler (1976), Erikson (1959/1968) y Shweder (1982) señalaron cómo el concepto de principio de Rawls y su asunción por parte de Kohlberg, era incapaz de captar la riqueza de los juicios morales o la complejidad de la vida moral. Estos aspectos lo condujeron nuevamente a una reformulación de su idea de moral y de las funciones que debería tener una psicología que se preocupara por el actuar ético de los sujetos. A esas nuevas formulaciones vamos a dedicar las siguientes líneas.

\section{La sabiduría y las últimas formulaciones éticas de Kohlberg}

En los años 80, Kohlberg se acercó a perspectivas bastante diferentes a las que había asumido en los años anteriores. Si las posturas del contrato social y las posturas deontológicas habían determinado su conceptualización de lo moral en las décadas anteriores, en sus últimos años de trabajo las teorías de la virtud, las visiones sobre la sabiduría y las consideraciones sobre las emociones impregnaron sus reflexiones sobre cómo caracterizar el discurso y acción moral. Concentrémonos en algunos de esos cambios.

La postura cognitiva de lo ético y la formulación de principios abstractos tuvieron una serie de críticas tanto desde posturas comunitaristas (McIntyre, 1987; Taylor, 1996, 2003; Sandel, 2000; Walzer, 1993), como de aquellos autores que abogaban por la consideración de las emociones y los sentimientos de compromiso y hermandad. En este apartado citaremos directamente a Kohlberg para ilustrar sus principales preocupaciones ${ }^{21}$.

21 En un texto de próxima aparición al mercado, nos extendemos de manera más precisa sobre estos desarrollos últimos de Kohlberg. Las limitaciones de espacio de este texto nos obliga ser más sintéticos y a exponer las ideas más importantes.
Con una nueva reflexión sobre como contemplar el juicio moral propone integrar los discursos sobre la justicia, con aspectos de benevolencia y preocupación por el otro. Después de nombrar a Sócrates, Gandhi, Lincoln y Martin Luther King escribe:

Cada uno estuvo comprometido, por supuesto, con una lucha por la justicia que les demandaba estar preparados para ofrendar sus vidas. Hubo seguramente también otros apasionados y revolucionarios lideres que nosotros no incluiríamos dentro del estadio 6: Robespierre, Marx, Lenin y otros. Estos líderes en nombre de la justicia entendían que el poder y la violencia eran medios legítimos de la acción moral. Desde nuestra perspectiva falta en estos líderes un balance compensatorio entre esta visión de la justicia y ese sentido que Erikson llama "simpatía vital" y que otros llaman Compasión. Por esto esos hombres no lograron ajustar la indignación por la injusticia a ese sentimiento de simpatía. Cada uno de esos líderes, que no incluimos en el sexto estadio, no poseen igualmente un segundo elemento que es vital para este sexto estadio: esto es el sentimiento de la moderación (Kohlberg, L, Higgins, A. \& Howard, R. 2000, 211)22.

Pero de la misma manera que incorpora la idea de la preocupación por el otro a través de su concepto de "simpatía activa", introduce igualmente otro tipo de motivaciones que se dirigen a explicar por qué las personas establecen unos compromisos y unos particulares sentimientos de obligación con las normas morales y con el bienestar de los otros. Frente a preguntas fundamentales de variadas tradiciones éticas (tanto kantianas como aristotélicas), como ¿por qué una persona se siente obligada a cumplir un mandato moral? ¿Por qué un ser humano habría de limitar su acción al acatar una norma que le restringe sus posibilidades de satisfacción?, Kohlberg y Power (1980), refiriéndose a sentimientos altruistas o benevolentes, recurren a un sentimiento de hermandad universal que se relaciona con un particular significado de lo religioso. Veamos como adelanta esta reflexión nuestro teórico del desarrollo moral.

22 Todas las traducciones de este texto son nuestras. 
La justicia universal remite a aquellos individuos, cuyos derechos han sido ignorados y que deben ser restablecidos nuevamente; la comunidad humana universal indica que todos somos hermanos y hermanas, que todos compartimos una común humanidad y que todos sentimos la esencia de la solidaridad colectiva. La justicia, la libertad y la igualdad deben ser complementadas por la hermandad. El enfoque de la comunidad humana universal al igual que aquellos de la justicia universal, son más que puntos de vista sobre la simpatía, la empatía, o la benevolencia. La simpatía, la empatía, la benevolencia, o el amor son posturas que nos ponen en relación con otro individuo. El logro de una comunidad humana se basa sobre un sentimiento de "inter-comunicación" universal. La empatía es un sentimiento admirable, pero ella no incluye la responsabilidad por todos los seres humanos. Ésta debe aplicarse a la membresía de toda la humanidad. La comunidad universal contempla no solamente la responsabilidad, sino la responsabilidad por la totalidad (Kohlberg, L.;

Higgins, A. \& Howard, R, 2000, 213).

Esta responsabilidad con todo el género humano e incluso con el mundo, como también lo sugiere Kohlberg, solo sería posible gracias a sentimientos religiosos. Lo religioso, además de su sentido etimológico de "re-ligar", de restablecer o constituir comunidad, es entendido por Kohlberg según los sentidos que le dieron Fowler (1981) y Erikson (1959/1968). Estas teorías son incorporadas en la conceptualización kohlbergiana para mostrar que un adulto en los últimos momentos de su vida de un adulto, solo ante la inminencia de la muerte, se pregunta por el sentido de la vida y por las posibilidades de la "trascendencia". Gracias a esta reflexión, el ser humano se enfrenta a la posibilidad de la integración y comunión con el universo, que es el sentido más claro de la idea de lo religioso. Kohlberg lo expresa de la siguiente manera:

Recurriremos a los estadios propuestos por Erikson (1959) y Fowler (1981) para caracterizar a los hombres de la adultez tardía como filósofos. Habremos de resaltar aquellos "estadios blandos" que refieren a la reflexión filosófica y religiosa sobre el sentido de la vida, especialmente el estadio octavo de Erikson que él denomina "Integridad vs. Desesperación" y los estadios quinto y sexto del modelo de desarrollo de la creencia, o del desarrollo ético y religioso de Fowler. Esa reflexión, esa meditación es ocasionada de cierta manera por la conciencia de la muerte y el establecimiento de los límites del sí-mismo (self), además de la posibilidad de crear algo, reproducirse, o criar nueva vida. Mientras que el aspecto de la "desesperación" frente a la muerte y los límites de la "generatividad" constituyen el polo negativo de la reflexión personal sobre el sentido de la vida en la adultez tardía, el polo positivo es constituido por representaciones sobre una perspectiva trascendente e infinita, que produce una sensación de integridad o totalidad. (Kohlberg, L. Shulik, R. \& Higgins, A. 2000d, 261).

La integridad y unión con el universo, los sentimientos de completud y responsabilidad, sumados a la conciencia de la incertidumbre y a la flexibilidad del juicio, caracterizan lo que Kohlberg, siguiendo a Erikson, denomina la sabiduría. La sabiduría es sola la expresión feliz de un camino lleno de incertidumbre, que conduce al juicio sin condiciones, sin certezas y que se nutre con miles de posibilidades que hacen de todo juicio un ejercicio de la intuición, la sensibilidad y la flexibilidad.

Con estos conceptos, Kohlberg pretende unir diferentes tradiciones en la discusión ética. Las posturas deontológicas se unen a las visiones aristotélicas y a perspectivas no cognitivas ${ }^{23}$. Si bien en sus años anteriores de trabajo había seguido celosamente las indicaciones deontológicas, en sus últimos años de trabajo, y especialmente en su obra póstuma (2000), incorporó aspectos opuestos en las tradiciones éticas. Los juicios morales no dependen ya de unos juicios universales, según los lineamientos kantianos, o rawlsianos, sino operan con unos sentimientos de hermandad y unos criterios de comunidad que

23 El libro citado en alemán (2000) fue producido por dos discípulos alemanes (Althof y Garz) originalmente en este idioma. Es el producto de una serie de manuscritos no publicados de Kohlberg. Posiblemente las imprecisiones y contradicciones que se puedan encontrar en ese texto puedan deberse a que se basa en borradores sueltos de nuestro autor. Borradores que no alcanzaron a ser editados y mejorados por el mismo autor. 
hacen que sean parte de particulares concepciones de realización y de solidaridad.

El concepto de sabiduría, a pesar de que la fuente citada por Kohlberg haya sido Erikson, se remonta a las indicaciones y reflexiones de los filósofos griegos y las posturas teleológicas que demandaban una consideración de las necesidades y concepciones de "vida buena" que los sujetos de una comunidad compartieran. Las versiones teleológicas, que para Kohlberg en sus iniciales teorizaciones eran un ejemplo de posturas relativistas, se sumaron en su teorización para poder captar las motivaciones y las significaciones variables de los sujetos que emiten juicios de justicia.

Posiblemente estas contradicciones generen una serie de interrogantes de naturaleza muy diferente. Abordaremos muchas de esas preguntas en otros textos, o acabarán siendo parte de la indagación de algunos de nuestros lectores. Nosotros, por ahora, nos ocuparemos de otros aspectos donde el interés investigativo de Kohlberg se adentró. Nos referimos a la psicología y la pedagogía.

\section{La psicología del desarrollo}

Hacia mediados del siglo anterior, Lawrence Kohlberg decide emprender la labor empírica de estudiar, desde una óptica lógico-evolutiva, cómo los seres humanos desarrollamos nuestros juicios morales, y cómo nos acercamos a los modos ideales de razonamiento que proponían las teorías ético-normativas.

Para tal fin, Kohlberg toma como punto de partida, además de las premisas expuestas en el apartado anterior, una serie de postulados de la psicología del desarrollo. La filosofía moral posibilitaba, según Kohlberg, establecer el estadio ideal hacia el que deberían tender todos los seres humanos. Ese estadio ideal permitiría no solamente sugerir una direccionalidad en este desarrollo, sino que además permitiría establecer los criterios para evaluar las capacidades de razonamiento de los individuos y establecer la distancia que estos tuvieran del punto final propuesto como ideal.

La asignación de funciones a las disciplinas hecha por Kohlberg limitaría a la psicología al trabajo empírico; es decir, la psicología debería asumir como tarea describir y explicar las dificultades que tuvieran los sujetos para razonar en los términos morales propuestos por las posturas éticas.

Para abordar esta tarea de indagación empírica, Kohlberg debió tomar posición en el debate existente en la psicología del desarrollo sobre la posibilidad de plantearse una direccionalidad o vección en el proceso de crecimiento infantil, sobre la posible dependencia del razonamiento de estructuras totales o de una serie de contenidos, o nociones independientes, sobre si el proceso de desenvolvimiento es parte de una tendencia de maduración biológica o si más bien es producto de una serie de enseñanzas pasivas de su medio social.

Sin creer necesario contextualizar y ampliar este debate, podemos afirmar que Kohlberg tomó partido con la tradición cognitivo-evolutiva de la psicología del desarrollo, representada en autores como George H. Mead (1934), James Mark Baldwin (1897), John Dewey (1911, 1916/1944) y Jean Piaget (1932/1987). Esta posición le permitió sugerir que el desarrollo sigue una dirección, que en el campo moral se orientaría hacia una progresiva capacidad en el razonamiento infantil de pensar en términos universales y según los principios de justicia. Igualmente, gracias a esta posición habría de establecer estadios, o cortes en el desarrollo caracterizados por capacidades globales universales ${ }^{24}$ de razonamiento y argumentación (Kohlberg, 1971b; Kohlberg, 1973; 1976; 1981; 1994).

Pero al igual que en el terreno filosófico, Kohlberg presentó variadas formas de entender y describir el desarrollo psicológico. Los criterios presentados, a pesar de que fueron formulados explícitamente por Kohlberg y de que fueron insistentemente defendidos por este autor, no siempre son coherentes con algunas particularidades psicológicas presentadas en su obra. A continuación presentaremos algunos criterios y descripciones

24 Siguiendo los lineamientos del interaccionismo simbólico, según Kohlberg, los aspectos más importantes del desarrollo moral son "culturalmente universales", porque todas las culturas tienen unos orígenes comunes de interacción social, de toma de ol, y de conflicto social que requieren una integración moral (Kohlberg, Levine y Heder, 1983) 
hechas por nuestro autor para ilustrar nuevamente sus variaciones conceptuales.

Kohlberg (1958) en su tesis doctoral no solo retomó el estudio inicial de Piaget sobre el criterio moral 25 y algunas ideas del interaccionismo simbólico, sino que propuso unos criterios bastante variados para el estudio de lo moral. Estos criterios fueron los siguientes: referían a una serie de respuestas que eran comunes a los sujetos de acuerdo a su edad.

Estos tipos ideales evolutivos fueron nominados y descritos por Kohlberg en su tesis doctoral de la siguiente forma (Kohlberg, 1958/1994):

Nivel 1: Premoral.

- Tipo 0: Orientación al castigo y la obediencia.

-Tipo 1: Ingenuo hedonismo instrumental.

\begin{tabular}{|c|c|c|}
\hline \multicolumn{3}{|c|}{ Aspectos codificados del juicio moral en desarrollo } \\
\hline Código & Descripción & Aspectos \\
\hline I. Valor & $\begin{array}{l}\text { Lugar exacto del valor-modos de } \\
\text { atribuir un valor moral a actos, per- } \\
\text { sonas o hechos. Modos de evaluar } \\
\text { las consecuencias de valor en una } \\
\text { situación. }\end{array}$ & $\begin{array}{l}\text { 1. Considerar los motivos al juzgar una acción. } \\
\text { 2. Considerar las consecuencias al juzgar la acción. } \\
\text { 3. Subjetividad contra objetividad de los valores evaluados. } \\
\text { 4. Relación de la obligación con el deseo. } \\
\text { 5. Identificación con el actor o las víctimas al juzgar la acción. } \\
\text { 6. Estatus del actor y de la víctima al cambiar el valor moral de las acciones. }\end{array}$ \\
\hline II. Elección & $\begin{array}{l}\text { Mecanismos para resolver o negar } \\
\text { la conciencia de los conflictos. }\end{array}$ & $\begin{array}{l}\text { 7. Limitar la responsabilidad del actor por las posibles consecuencias delegando la } \\
\text { responsabilidad a otros. } \\
\text { 8. Confianza en la discusión y el compromiso, principalmente de manera no realista. } \\
\text { 9. Distorsionar la situación de forma que la conducta conformista parezca que siem- } \\
\text { pre maximice los intereses del actor o de otros involucrados }\end{array}$ \\
\hline $\begin{array}{l}\text { III. Sancio- } \\
\text { nes y moti- } \\
\text { vos }\end{array}$ & $\begin{array}{l}\text { Los motivos y sanciones para la ac- } \\
\text { ción o desviación moral. }\end{array}$ & $\begin{array}{l}\text { 10. Castigo o reacciones negativas. } \\
\text { 11. Ruptura de una relación interpersonal. } \\
\text { 12. Preocupación del actor por el bienestar y estado positivo del otro. } \\
\text { 13. Auto-condena. }\end{array}$ \\
\hline IV. Reglas & $\begin{array}{l}\text { Las formas en que las reglas se con- } \\
\text { ceptualizan, aplican y generalizan. } \\
\text { La base de validez de una regla. }\end{array}$ & $\begin{array}{l}\text { 14. Definición de un acto como desviado (definición de reglas y normas morales). } \\
\text { 15. Generalidad y consistencia de las reglas. } \\
\text { 16. Abandono de las reglas por unas relaciones personales (particularismo). }\end{array}$ \\
\hline $\begin{array}{l}\text { V. Derechos } \\
\text { y autoridad }\end{array}$ & $\begin{array}{l}\text { Base y límites del control sobre las } \\
\text { personas y la autoridad. }\end{array}$ & $\begin{array}{l}\text { 17. Atributos no motivacionales atribuidos a la autoridad. } \\
\text { 18. Extensión o campo de los derechos de la autoridad. Derechos de la libertad. } \\
\text { 19. Derechos de propiedad o posesión. }\end{array}$ \\
\hline $\begin{array}{l}\text { VI. Justicia } \\
\text { positiva }\end{array}$ & Reciprocidad e igualdad. & $\begin{array}{l}\text { 20. Intercambio y reciprocidad como un motivo para la conformidad de rol. } \\
\text { 21. Reciprocidad como un motivo para desviarse. } \\
\text { 22. Justicia distributiva. Igualdad e imparcialidad. } \\
\text { 23. Conceptos de mantenimiento de las expectativas del compañero como un motivo } \\
\text { para la conformidad. }\end{array}$ \\
\hline $\begin{array}{l}\text { VII. Justicia } \\
\text { punitiva }\end{array}$ & Estándares y funciones del castigo. & $\begin{array}{l}\text { 24. Tendencias o expectativas punitivas. } \\
\text { 25. Funciones o intención del castigo. }\end{array}$ \\
\hline
\end{tabular}

En función de estos criterios, Kohlberg planteó sus primeras propuestas del desarrollo del juicio moral. En su primera formulación, se acercó a las ideas weberianas de los tipos ideales' ${ }^{26}$, los cuales se

25 Piaget tuvo unos cambios conceptuales igualmente marcados. En los años de 1920 a 1935 (durante los cuales escribió su texto "el criterio moral en el niño") tenía una concepción cercana a las teorías de la socialización del interaccionismo simbólico. Posteriormente entre los años 1935 y 1970 postuló su teoría estructuralista genética en la que se distanciaba de las explicaciones sociales en el desarrollo. Posteriormente, a partir de los años 70 se acercó a las teorías del desarrollo procedimentales de corte computacional. Estas variaciones de Piaget, no son claramente diferenciadas en Kohlberg, quien retoma algunas de sus diferentes ideas.

26 Este concepto de tipo ideal estaba presente igualmente en los primeros trabajos de Piaget y era común en muchos autores del interaccionismo simbólico.
Nivel 2 : Moralidad de conformidad con el rol convencional.

-Tipo 2: Moralidad de mantenimiento de buenas relaciones, aprobación por parte de otros.

-Tipo 3: Moralidad del mantenimiento de la autoridad.

Nivel 3: Moralidad de principios morales autoaceptados.

-Tipo 4: Moralidad de compromiso, de derechos individuales y de la ley democráticamente aceptada.

-Tipo 5: Moralidad de principios individuales de conciencia. 
Estos niveles y estadios del desarrollo formulados en su tesis doctoral difieren de los presentados en otros textos posteriores, no solo por la numeración de los estadios (en esta formulación empieza por un estadio 0 ), sino por su caracterización. Veamos algunas de esas diferencias.

Cuatro años después de la presentación de su primer modelo, Kohlberg presenta una nueva versión de desarrollo en la que modifica algunos aspectos. El primer aspecto modificado fue el referido a la nominación de los niveles del juicio moral. Así, Kohlberg (1962) adoptó los términos preconvencional, convencional y postconvencional para definir más sencillamente los tres niveles de su esquema de desarrollo. El uso de los prefijos pre y post, antepuestos al término convencional, permite entonces hacer más pronta la referencia al nivel en cuestión. En el nivel preconvencional, la persona no ha llegado todavía a entender y mantener las normas sociales convencionales. En el nivel post-convencional, la persona entiende y acepta, en general, las normas de la sociedad, pero esta aceptación no es por razones impuestas por la mayoría, ni por preocupaciones referidas a la autoridad, sino que esta aceptación se condiciona al cumplimiento de principios morales universales.

El segundo cambio, algo más importante, es la sustitución del término tipo por el término estadio. Ya en su tesis doctoral del 58, Kohlberg había sugerido que sus tipos morales podrían igualarse a estadios, dado que las respuestas resultaron normativas (en el sentido de generalizables), claras y lógicas, y que la organización de los tipos fue expresada de forma correlacional, evidenciando una notable diferencia entre los grupos de edad. Sin embargo, es solo hasta 1962 que decide utilizar el concepto de estadio para caracterizar las diferentes fases por las que atraviesa el desarrollo del juicio moral. Ello implica que en ese momento Kohlberg se siente en la capacidad de aseverar que sus niveles del juicio moral cumplen con todas las características que deben tener los estadios según la formalización piagetiana (es decir, son una construcción jerárquica, que forman un todo estructurado, cualitativamente único y que cursan una secuencia universal e invariable) ${ }^{27}$.

El tercer cambio en la reformulación de 1962 tiene que ver con la numeración de los estadios, como ya lo mencionamos. Los estadios dejaron de ser una secuencia del cero al cinco, para serlo del uno al seis. Este es un cambio simple, pero notorio, cuyas razones no fueron explicitadas por Kohlberg.

El cuarto cambio está ligado al primero. No solo los niveles cambian de nombre, los estadios también lo hacen. Ya no se definen según el tipo de moralidad que evidencian sino por la orientación del juicio. Así el primer estadio conserva su nombre de orientación al castigo y la obediencia, el segundo se renombra como orientación instrumental-relativista (o ingenuamente egoísta), el tercero se denomina ahora como orientación de concordancia personal (o del buen chico), el cuarto se rebautiza como orientación del mantenimiento de la ley y el orden social, el quinto se transforma en la orientación legalista-contractual, y el último recibe por nombre orientación de los principios universales (o de conciencia) (Kohlberg, 1969). Asociado a esta variación terminológica, obviamente, Kohlberg presenta algunas variaciones en la caracterización de los estadios.

En la tabla a continuación está la forma en que presenta Kohlberg los estadios en 1962 (Kohlberg, 1969, 1980).

Desde la primera reformulación de su modelo en 1962, fueron muchos los hechos y debates que llevaron a Kohlberg a considerar otros aspectos dentro de su modelo y a reformular nuevamente su caracterización del juicio moral y su desarrollo.

Según Bergling (citado por Peltzer, 1986) el pionero de la psicología del desarrollo moral presentó seis (6) diferentes versiones de los estadios y del desarrollo psicológico ente los años 1964 y 1977. Nosotros añadiríamos otras versiones propuestas por el mismo autor en los años 80. Dado el espacio del que disponemos, nos limitaremos a nombrar algunos nuevos conceptos asociados al problema del desarrollo que Kohlberg formuló después del año 1976.

27 Como se notará, en esta época las referencias hechas a Piaget tienen en cuenta el periodo estructural de este autor. 


\begin{tabular}{|c|c|c|c|}
\hline \multicolumn{4}{|c|}{ Formulación de los niveles del juicio moral según Kohlberg, 1962} \\
\hline Nivel & Características & Bases del juicio & Estadios de desarrollo \\
\hline \multirow[t]{2}{*}{$\begin{array}{l}\text { Preconven- } \\
\text { cional }\end{array}$} & \multirow{2}{*}{$\begin{array}{l}\text { La persona que justifica sus de- } \\
\text { cisiones morales en este nivel es } \\
\text { sensible a las reglas culturales y } \\
\text { a lo que es etiquetado como bue- } \\
\text { no o malo socialmente hablando. } \\
\text { Evita transgredir aquellas normas } \\
\text { sancionadas con castigos, debi- } \\
\text { do a que teme el poder superior } \\
\text { de la autoridad y las consecuen- } \\
\text { cias negativas de la infracción. }\end{array}$} & \multirow{2}{*}{$\begin{array}{l}\text { El valor moral re- } \\
\text { side en aconteci- } \\
\text { mientos o necesi- } \\
\text { dades externas o } \\
\text { cuasifísicas, más } \\
\text { que en las perso- } \\
\text { nas y estándares } \\
\text { sociales. }\end{array}$} & $\begin{array}{l}\text { 1. Orientación al castigo y la obediencia. Referencia egocéntrica al } \\
\text { poder o prestigio superiores, o una tendencia a evitar problemas. } \\
\text { Las consecuencias físicas evidentes determinan si una acción o una } \\
\text { decisión moral son buenas o malas. Responsabilidad objetiva. }\end{array}$ \\
\hline & & & $\begin{array}{l}\text { 2. Orientación ingenuamente egoísta. La razón para la acción es la } \\
\text { satisfacción de las propias necesidades e intereses, en un mundo } \\
\text { en donde se reconoce que cada persona tiene intereses personales. } \\
\text { Las relaciones humanas se ven en términos de intereses negocia- } \\
\text { bles. La reciprocidad aquí no se da en términos de lealtad, gratitud } \\
\text { o justicia, sino de provecho. }\end{array}$ \\
\hline \multirow[t]{2}{*}{$\begin{array}{l}\text { Convencio- } \\
\text { nal }\end{array}$} & \multirow{2}{*}{$\begin{array}{l}\text { Quien justifica sus juicios en este } \\
\text { nivel tiene una perspectiva de } \\
\text { miembro de la sociedad, esto es, } \\
\text { se ha identificado con las reglas } \\
\text { y las expectativas de otros, y las } \\
\text { ha interiorizado, en especial las } \\
\text { de la autoridad. Ya no tiene tan } \\
\text { en cuenta las consecuencias in- } \\
\text { mediatas de las acciones y la ac- } \\
\text { titud que mantiene no es sólo de } \\
\text { búsqueda de satisfacción perso- } \\
\text { nal, sino de lucha por mantener, } \\
\text { apoyar y justificar el orden social. }\end{array}$} & \multirow{2}{*}{$\begin{array}{l}\text { El valor moral } \\
\text { reside en inter- } \\
\text { pretar roles bue- } \\
\text { nos o correctos, } \\
\text { en mantener el } \\
\text { orden y las ex- } \\
\text { pectativas de los } \\
\text { demás. }\end{array}$} & $\begin{array}{l}\text { 3. Orientación del buen chico. Lo que está bien es vivir de acuerdo } \\
\text { con lo que esperan las personas próximas a cada quien (ser un buen } \\
\text { hijo, un buen amigo, etc.). Existe conformidad con las imágenes es- } \\
\text { tereotípicas de buen comportamiento. La conducta frecuentemente } \\
\text { es juzgada por su intención. }\end{array}$ \\
\hline & & & $\begin{array}{l}\text { 4. Orientación de mantenimiento de la ley y el orden social. El fin úl- } \\
\text { timo es mantener la institución en su conjunto, con lo cual evita cual- } \\
\text { quier ruptura del sistema. Se debe cumplir con los deberes actuales } \\
\text { con los que se está de acuerdo. Las leyes deben ser respetadas y } \\
\text { defendidas, excepto en los casos en que entran en conflicto con } \\
\text { deberes establecidos. }\end{array}$ \\
\hline \multirow[t]{2}{*}{$\begin{array}{l}\text { Postcon- } \\
\text { vencional }\end{array}$} & \multirow[t]{2}{*}{$\begin{array}{l}\text { Aquél que razona dentro de este } \\
\text { nivel antepone sus principios mo- } \\
\text { rales a las normas grupales o in- } \\
\text { tereses de personas particulares, } \\
\text { y define sus valores como princi- } \\
\text { pios autoimpuestos. }\end{array}$} & \multirow[t]{2}{*}{$\begin{array}{l}\text { El valor moral } \\
\text { reside en la con- } \\
\text { formidad del ego } \\
\text { con estándares, } \\
\text { derechos o debe- } \\
\text { res compartidos } \\
\text { o compartibles. }\end{array}$} & $\begin{array}{l}\text { 5. Orientación legalista contractual. Se es consciente de que la gen- } \\
\text { te mantiene una variedad de valores y opiniones, y de que la mayoría } \\
\text { de éstos son relativos a los grupos, sin embargo, se entiende que } \\
\text { algunos de estos valores no son relativos, como la vida y la libertad. } \\
\text { Se cree en la validez de los principios morales universales y se tiene } \\
\text { un sentido de compromiso personal con ellos. } \\
\text { El deber se define en términos de contrato, evitando la violación de } \\
\text { los derechos de otros y según la voluntad y bienestar de la mayoría. }\end{array}$ \\
\hline & & & $\begin{array}{l}\text { 6. Orientación de conciencia. Los derechos son definidos por deci- } \\
\text { siones de conciencia de acuerdo con principios éticos de universa- } \\
\text { lidad. Se defienden los principios universales de justicia, reciproci- } \\
\text { dad, igualdad de derechos y respeto a la dignidad del otro como ser } \\
\text { humano individual, racional y valioso. } \\
\text { En el caso de que los principios entren en conflicto con las normas } \\
\text { de la sociedad, el individuo postconvencional juzga por los principios } \\
\text { más que por los acuerdos. } \\
\text { Esta orientación es ejemplificada por el pensamiento de Jesucristo, } \\
\text { Gandhi y Martin Luther King. }\end{array}$ \\
\hline
\end{tabular}

Los cambios en la caracterización de los estadios, la inclusión de las ideas de la cognición social de Selman (1980), los estadios intermedios 4-1/2 y $51 / 2$, los subestadios A y B, las diferencias en el desarrollo entre el juicio y la acción, la eliminación e incorporación en diferentes momentos del estadio 6, la idea del desarrollo según el concepto de sabiduría de la psicología del ciclo vital, entre otras variaciones, muestran la constante variación de su teorización psicológica (1976; 1980; 1982, 1987b; Kohlberg, Levine y Heder, 1983a).

Las variaciones en su teoría de los estadios se debieron tanto a las críticas recibidas como a aspectos propios del desarrollo de la psicología evolutiva.
Lamentablemente, Kohlberg no precisa suficientemente las razones de sus cambios conceptuales sobre el desarrollo humano, ni se preocupa por mantener una coherencia entre sus múltiples teorizaciones. Debido a que el objetivo de este escrito es presentar un panorama de nuestro trabajo de investigación sobre la obra de Kohlberg, pasamos rápido por algunas razones que explicarían sus constantes variaciones para dirigir nuestras palabras hacia otro de los campos donde Kohlberg ha dejado su impronta. En un futuro cercano publicaremos un texto más extenso donde estos aspectos sean señalados. Por ahora seguimos con las propuestas pedagógicas de nuestro pionero americano. 


\section{Kohlberg y la educación moral}

Nadie que en la actualidad se encuentre interesado en investigar sobre educación moral puede pasar por alto la obra de Lawrence Kohlberg. Su trabajo en esta área tuvo una importante resonancia mundial y despertó el interés de muchos psicólogos y educadores que, como él, creen que el propósito de la educación moral no es hacer niños buenos sino hacer lo posible para que los niños desarrollen al máximo sus intuiciones y juicios morales con el fin de que puedan ponerlos en práctica en la interpretación y solución de problemas del ámbito moral28 (Yáñez y Fonseca, 2003, 2004).

Lawrence Kohlberg (1987d) fue el primero que propuso una teoría que explicara la forma como los niños en diferentes momentos de su desarrollo razonan sobre problemas morales, y también el primero en desarrollar una propuesta educativa que facilitara e impulsara el desarrollo del juicio moral, al entender tal desarrollo en relación con el logro de la autonomía de los individuos y con la progresiva complejización de aquellos juicios que tienen relación con aspectos de justicia, igualdad y respeto a las personas y su dignidad.

Por ello es ineludible destinar un apartado dentro de este escrito para realizar una presentación del contexto histórico en el que se inscribe su aproximación educativa y las diferencias entre esta y algunas otras estrategias pedagógicas encaminadas al desarrollo del juicio moral y los valores.

A pesar de que la ciencia y la pedagogía tendrían por tarea estudiar los hechos empíricos y proponer los medios para lograr ciertos objetivos, Kohlberg recurre nuevamente a una particular concepción de la filosofía para establecer cuáles deberían ser los fines que debe perseguir cualquier propuesta pedagógica. Mediante este análisis puede encontrarse en Kohlberg desde justificaciones de la educación moral en la filosofía de Platón, Aristóteles, Dewey y Piaget, hasta clasificaciones de las posturas pedagógicas en esquemas bastante generales $y$, por qué no decirlo, un poco simplificadores de las posiciones

28 Para Kohlberg (1971b) el desarrollo moral debe ser un objetivo intrínseco de la educación. que él considera se opondrían a las posiciones por él defendidas. Ubicar la relación entre Platón, Aristóteles, Dewey y Piaget, por citar algunos autores que permitirían desarrollar su perspectiva "progresiva", es un problema que poco parece inquietar a Kohlberg. Sin embargo, intentando seguir su manera de razonar, evitaremos hacer un análisis sobre las posibles contradicciones de los autores sobre los que pretende cimentar su propuesta. Nos remitiremos a las exposiciones que hace nuestro autor en relación con alguna preocupación filosófica particular, o con algún propósito educativo específico.

Si Dewey, Mead, Piaget y los demás autores de la tradición progresiva de la educación le permiten a Kohlberg justificar el proceso educativo como un proceso de equilibrio entre las posibilidades del sujeto que aprende y las demandas del ambiente, que progresivamente conduce a la autonomía y a juicios cada vez más universales, Platón y Aristóteles le permiten justificar su objetivo educativo de desarrollar en los sujetos un sentido de justicia y una capacidad para ser coherente y consecuente en sus individuales actos morales.

A juicio de Kohlberg (1970), el primer autor que debe ser considerado para desarrollar una propuesta para la educación moral es Platón. Independientemente de la concepción griega de virtud y de la defensa kantiana de los principios que hace Kohlberg, Platón es resaltado por nuestro autor porque entiende la virtud como parte de un conocimiento para el bien y porque este bien puede y debe ser enseñado ${ }^{29}$. La justicia, que sería la máxima virtud, permitiría reconocer el bien y rechazar el mal y el comportamiento inadecuado para los seres humanos y la propia comunidad.

Platón es pues el punto de partida de Kohlberg en la formulación de su modelo pedagógico hacia el desarrollo moral, puesto que no solo resalta la importancia de la justicia, sino que llama al educador

29 Entendiendo enseñar como diferente a instruir, que significa informar. La enseñanza del bien se hace mediante la formulación de preguntas reflexivas y la observación de distintos puntos de vista, no mediante instrucciones, ya que para Platón la educación moral debe conducir al hombre en sentido ascendente, evitando que el conocimiento se quede intacto en la mente (Kohlberg, 1970). 
a utilizar un método reflexivo (socrático) como estrategia pedagógica.

Partiendo de su teoría del desarrollo moral, Kohlberg formula algunas certezas prácticas sobre el razonamiento platónico: (1) que el concepto del bien es universal; (2) que la madurez moral implica mucho más que una tarea intelectual o cognitiva; y (3) que cada estadio representa un postura particular sobre el bien, siendo cada uno parte de un proceso de acercamiento a un nivel más alto y universal de principios morales que conectan el respeto por la ley y los derechos humanos mediante un claro sentido de justicia (Kohlberg, 1970; Kohlberg, Noam, Snarey, 1983/1987).

De allí que, según Kohlberg, el primer paso para la enseñanza de la virtud sería crear en el estudiante una insatisfacción sobre su conocimiento del bien, a través del modelo socrático de discusión o de la exposición del estudiante a conflictos en los cuales sus herramientas (conocimiento del bien) se muestren como insuficientes. El segundo paso consistiría en exponer al estudiante a la discrepancia y contrargumentación de sus pares o de personas en un nivel superior de desarrollo moral (herramienta que encuentra más efectiva), ya que cree, al igual que Aristóteles (1993), que las virtudes morales se obtienen mediante su propio ejercicio (Kohlberg, 1970).

La referencia a las obras de Platón y Aristóteles refleja una preocupación particular por la educación moral. Inicialmente al simpatizar expresamente con la teoría de Dewey, plantea que lo fundamental de la educación moral sería que el sujeto desarrollara la capacidad para reflexionar y analizar de manera autónoma las diferentes situaciones (Kohlberg, 1970). Posteriormente, al reconocer la importancia de la acción, y el compromiso personal con determinados grupos, recurre a las ideas platónicas y aristotélicas. El desarrollo de la virtud se hace posible, según lo formula en textos tardíos de su obra intelectual, en el ejercicio cotidiano de la democracia y en la constitución de una comunidad justa. Gracias a la experiencia de vivir en una colectividad democrática, donde los maestros propicien la participación de todos los estamentos de la escuela, los niños aprenden a manejar los principios democráticos y a realizar acciones justas en su actuar cotidiano.

La historia de las reflexiones de Kohlberg sobre la educación oscila entonces desde una preocupación por el desarrollo del juicio individual hasta la creación de una atmósfera democrática donde los sujetos puedan negociar sus reglas y sus normas de convivencia. Inicialmente considera que la mejor estrategia de la educación moral es enfrentar al sujeto a una serie de dilemas morales. Posteriormente establece la idea de la comunidad justa, donde el sujeto es involucrado, y comprometido, en ciertos estamentos de discusión y decisión democrática. En este último caso no basta la discusión de dilemas, sino que lo fundamental de la formación es la participación del sujeto en todos los procesos de constitución y control de las normas de una determinada colectividad.

Obviamente, estos cambios conceptuales van apareados de un sinnúmero de concepciones sobre la educación y sobre sus ideas de lo moral. La comprensión de lo moral, la eliminación del estadio 6 como objetivo de la educación, la formulación del estadio 4 como propósito general del sistema educativo, la idea de lo moral como parte de un juicio del sujeto, o como expresión de unos valores compartidos por la comunidad, son tan solo algunos de esos problemas y conceptos que adquirieron una particular significación en las reflexiones e intervenciones de Kohlberg en el ámbito educativo (Kohlberg, Power y Higgins, 1989/1997; Kohlberg, Hickey y Scharf, 1972).

Los diferentes campos o problemas donde Kohlberg incursionó reflejan su poco interés integrador y su a veces visión pragmática de la teoría. Cada tema y cada problema parece despertaran, en nuestro famoso neoyorquino, una conceptualización particular, sin que esto le generara una explícita preocupación por la coherencia. La importancia de este icono de la psicología y de los temas que por el fueron trabajados, nos compromete a presentar en un futuro próximo una más completa narración sobre la historia intelectual de Lawrence Kohlberg. 


\section{Referencias}

Aristóteles. (1993). Ética nicomáquea. Madrid: Planeta.

Baldwin, J. (1897). Social and ethical interpretations in mental development. New York: Macmillan.

Des Jardin, J. (1980). A philosophical analysis of Lawrence Kohlberg's theory of moral development. Ph.D. dissertation, University of Notre Dame.

Dewey, J. (1911). Moral principles in education. Boston: Houghton Mifflin.

Dewey, J (1916/1944). Democracy and education. New York: Macmillan.

Eckensberger, L. \& Reinshagen, H. (1980). Kohlberg's stage theory of the development of moral judgment: An attempt at reinterpretation from an action theory framework. En L. Eckensberger \& R. Silbereisen (Eds.), Development of social cognition: Models, theories, methods, application. Stuttgart-Germany: Klett-Cotta.

Erikson, E. (1959/1968). Identidad, juventud y crisis. Buenos Aires: Paidós.

Fowler, J. (1976) Stages in faith: The structural development approach. En T. Hennessey (ed.), Values and moral development. New York: Paulist Press.

Fowler, J. (1981). Stages of faith: The psychology of human development and the quest for meaning. New York: Harper \& Row.

Gilligan, C. (1977). In a different Voice- Women's Conception of Self and of Morality. In Harvard Education Review, 47, 481-517.

Gilligan, C. (1982/1985). La moral y la teoría: Psicología del desarrollo femenino. México: Fondo de Cultura económica.

Habermas, J. (1979). Moral development and ego identity. En Comunication and the evolution of society. Translated by T. McCarthy. Boston Beacon Press.

Hare, R. (1963). Freedom and Reason. New York: Oxford University Press.

Kant, I. (1785/1959). Foundations of the metaphysics of morals. Traducido al inglés por L. Beck. Indianapolis: Bobbs-Merrill.

Kegan, R. (1982). The Evolving Self. Cambridge: Cambridge University Press.

Kohlberg, L. (1958/1994). Kohlberg's original study of moral development ("The development of modes of thinking and choices in years 10 to 16"). New York: Garland Publishing.
Kohlberg, L. (1969/1992). Estadio y secuencia. En L. Kohlberg (1992), Psicología del desarrollo moral. Bilbao: Editorial Desclée de Brouwer. (Publicado originalmente en inglés en 1984 con el título: Essays in moral development, Volume II. The psychology of moral development: Moral stages and the life cycle. San Francisco: Harper and Row). (Este texto es una compilación de artículos publicados en diferentes fechas).

Kohlberg, L. (1970). Education for Justice: A Modern Statement of the Platonic View. En T. Sizer (Ed.), Moral Education. Five lectures. Cambridge, Massachusetts: Harvard University Press.

Kohlberg, L. (1971b). From is to ought: How to commit the naturalistic fallacy and get away with it in the study of moral development. En L. Kohlberg (1981), Essays in moral development. Volume I. The philosophy of moral development. Moral stages and the idea of justice. San Francisco: Harper and Row.

Kohlberg, L. (1973/1994). The claim to moral adequacy of a highest stage of moral judgment. En B. Puka (Ed.), Moral Development. A compendium (pp. 2-18). New York \& London: Garland Publishing Inc.

Kohlberg, L. (1976). Estadios Morales y Moralización: La Vía Cognitivo-Evolutiva. En L. Kohlberg (1992). Psicología del desarrollo moral. Bilbao: Editorial Desclée de Brouwer. (Publicado originalmente en inglés en 1984 con el título: Essays in moral development. Volume II. The psychology of moral development: Moral stages and the life cycle. San Francisco: Harper and Row.

Kohlberg, L. (1977). The future of liberalism as the dominant ideology of the west. En L. Kohlberg (1981). Essays in moral development. Volume I. The philosophy of moral development. Moral stages and the idea of justice. San Francisco: Harper and Row.

Kohlberg, L. (1978). Justice as reversibility: the claim to moral adequacy of a highest stage of moral judgment. En L. Kohlberg (1981), Essays in moral development. Volume I. The philosophy of moral development. Moral stages and the idea of justice. San Francisco: Harper and Row

Kohlberg, L. (1980). High School Democracy And Educating For A Just Society. En R. Mosher (Ed.). Moral Education. A first generation of research and development. New York: Praeger Publishers. 
Kohlberg, L. (1981). Essays in moral development. Volume I. The philosophy of moral development. stages and the idea of justice. San Francisco: Harper and Row.

Kohlberg, L. (1982). Moral development does not mean liberalism as destiny: A reply to Rick Shweder. En Contemporary Psychology, Vol. 28 (No 1), 80-82.

Kohlberg, L. (1987b). Conscience As Principled Responsibility: On The Philosophy Of Stage Six. En Conscience: An interdisciplinary view. Salzburg Colloquium on Ethics in the Sciences and Humanities. Dordrecht, Holland: D. Reidel publishing company.

Kohlberg, L. (1987d). El enfoque cognitivo-evolutivo de la educación moral. En F. Santolaria y J. Jordán (Comps.), La educación moral, hoy. Cuestiones y perspectivas. Barcelona: PPU.

Kohlberg, L. (1984/1992). Psicología del desarrollo moral. Bilbao: Editorial Desclée de Brouwer. (Publicado originalmente en inglés en 1984 con el título: Essays in moral development. Volume II. The psychology of moral development: Moral stages and the life cycle. San Francisco: Harper and Row)

Kohlberg, L. (2000). Die Psichologie der Lebenspanne. Obra póstuma editada y corregida por W. Althof \& D. Garz. Frankfurt/main: Suhrkamp.

Kohlberg, L. Hickey, J. y Scharf, P. (1972). The justice structure of the prison: A theory and intervention. En Prison journal (№. 51), 3-14.

Kohlberg, L, Higgins, A. y Howard, R. (2000). Der Erwachsene als Philosoph. En Die Psichologie der Lebenspanne. Obra póstuma editada y corregida por W. Althof \& D. Garz. Frankfurt/main: Suhrkamp.

Kohlberg, L, Levine, C. y Heder, A. (1983a). La Formulación Actual De La Teoría. En L. Kohlberg (1992). Psicología del desarrollo moral. Bilbao: Editorial Desclée de Brouwer. (Publicado originalmente en inglés en 1984 con el título: Essays in moral development. Volume II. The psychology of moral development: Moral stages and the life cycle. San Francisco: Harper and Row).

Kohlberg, L, Noam, G. y Snarey, J. (1983/1987). Ego development and education: A structural perspective. En L. Kohlberg, R. DeVries, G. Fein, D. Hart, R. Mayer, G. Noam, J. Snarey y J. Wertsch (1987), Child psychology and childhood education. A cognitive-development view. Longman: New York. (Publicado originalmente en Developmental Review, Vol.3, 1983).
Kohlberg, L, y Power, C. (1980). Religion, Morality, and Ego Development. En J. Fowler \& A. Vergote (Eds.). Toward moral and religious maturity. The first international conference on moral and religious development. Morristown, New Jersey: Silver Burdett Company.

Kohlberg, L, Power, C. y Higgins, A. (1989/1997). La Educación Moral Según Lawrence Kohlberg. Barcelona: Gedisa Editorial. (Libro publicado originalmente en inglés en mayo de 1991 bajo el título Lawrence Kohlberg's approach to moral education . Columbia University Press).

Kohlberg, L, Shulik, R. y Higgins, A. (2000d). Der altere Mensch als Philosoph. En Die Psichologie der Lebenspanne. Obra póstuma editada y corregida por W. Althof \& D. Garz. Frankfurt/main: Suhrkamp.

Lind, G. (1999). Una introducción al Test del juicio moral (MJT). Traducido por Manuel José Salazar. Bogotá, Colombia. Documento original recuperado de: http://www.uni-konstanz.de/ag-moral/b-publik.htm

Loevinger, J. (1977). Ego Development. San Francisco: Jossey-Bass.

MacIntyre, A. (1987). Tras la virtud. Barcelona: Crítica.

Mead, G. (1934). Mind, self and society. Chicago: University of Chicago Press.

Oser, F. (2001). Acht Strategien der Wert- und Moralerziehung. En W. Edelstein, F. Oser, \& P. Shuster (2001), Moralische Erziehung in der Schule: Entwicklungspsychologie und pädagogische Praxis. Weinheim: Beltz Verlag.

Peltzer, U. (1986). Lawrence Kohlbergs Theorie des moralischen Urteilens. Westdeutscher Verlag. Opladen.

Piaget, J. (1932/1987). El criterio moral en el niño. Barcelona: Martínez Roca.

Rawls, J. (1971). A theory of justice. Cambridge, MA: Harvard University Press.

Sandel, M. (2000). El liberalismo y los límites de la justicia. Barcelona: Gedisa.

Selman, R. (1980). The growth of interpersonal understanding: Developmental and clinical analyses. New York: Academic Press.

Shweder, R. (1982). Liberalism as Destiny. Review of Lawrence Kohlberg's "Essays on Moral Development. Volume 1. The Philosophy of Moral Development: Moral Stages and the Idea of Justice". En Contemporary Psychology, Vol. 27 ( $\mathrm{N}^{\circ}$ 6), 421- 424. 
Taylor, C. (1996). Fuentes del yo: la construcción de la identidad moderna. Barcelona: Paidós.

Taylor, C. (2003). El multiculturalismo y "la política del reconocimiento". España: Fondo de Cultura Económica.

Walzer, M. (1993). Las esferas de la justicia. México: Fondo de Cultura Económica.

Yánez, J. y Fonseca, M. (2003). Teorías y narraciones sobre la educación moral. En Revista Colombiana de Educación (No 45), 118-143. Bogotá: DGP- Universidad Pedagógica Nacional

Yánez, J. y Fonseca, M. (2004). Kohlberg y la educación moral. En E. Aguirre y J. Yáñez (Eds.), Diálogos 3. Discusiones en la psicología contemporánea (pp. 5593). Bogotá: Universidad Nacional de Colombia. 